\title{
A novel surgical technique for the repair of coronary obstruction after arterial switch operation
}

Hisao Nagato, MD, Kenta Imai, MD, Akio Ikai, MD, and Kisaburo Sakamoto, MD, Shizuoka, Japan

\author{
From the Department of Cardiovascular Surgery, Mt. Fuji Shizuoka Children's Hospital, Shizuoka, Japan. \\ No specific funding was provided for this work. \\ Disclosures: Authors have nothing to disclose with regard to commercial support. \\ Received for publication Nov 15, 2018; revisions received Dec 26, 2018; accepted for publication Jan 6, 2019; \\ available ahead of print Feb 22, 2019. \\ Address for reprints: Hisao Nagato, MD, Mt Fuji Shizuoka Children's Hospital, 860 Urushiyama, Aoi-ku, \\ Shizuoka 420-8660, Japan (E-mail: hisao.nagato@hotmail.com). \\ J Thorac Cardiovasc Surg 2019;158:e17-9 \\ $0022-5223 / \$ 36.00$ \\ Copyright (C) 2019 by The American Association for Thoracic Surgery \\ https://doi.org/10.1016/j.jtcvs.2019.01.017
}

Video clip is available online.

Arterial switch operation (ASO) is a standard procedure for the transposition of the great arteries that carries low operative mortality and morbidity. Reoperations, however, are still necessary in some cases. Coronary obstruction is the most challenging complication after ASO. Patch angioplasty or bypass grafting is reported as the treatment of choice. ${ }^{1-3}$ We describe the introduction and outcomes of a novel patch angioplasty technique for a 4-year-old boy.

\section{TECHNIQUE}

A boy with a diagnosis of complete transposition of the great arteries type II had undergone an ASO by way of

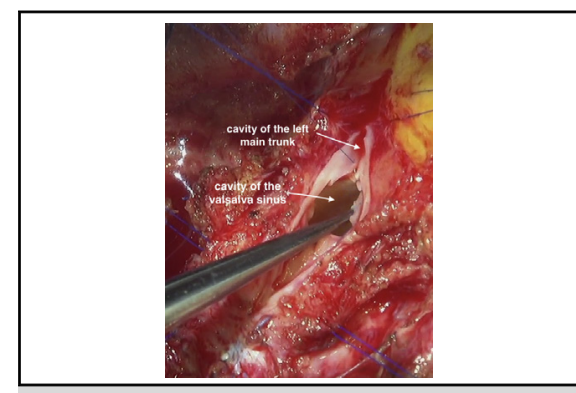

A new coronary orifice: left main trunk floor and Valsalva wall were incised and sutured.

\section{Central Message}

We successfully introduced a novel patch angioplasty technique to treat coronary obstruction after arterial switch operation, which involves new distal orifice creation to obtain a shorter main trunk.

See Commentary on page e21.

the Lecompte maneuver and ventricular septal defect closure at another hospital at 10 days after birth. The left coronary artery (anterior descending and circumflex) originated from sinus 1 , and the right coronary artery originated from sinus 2. Angiography at postoperative
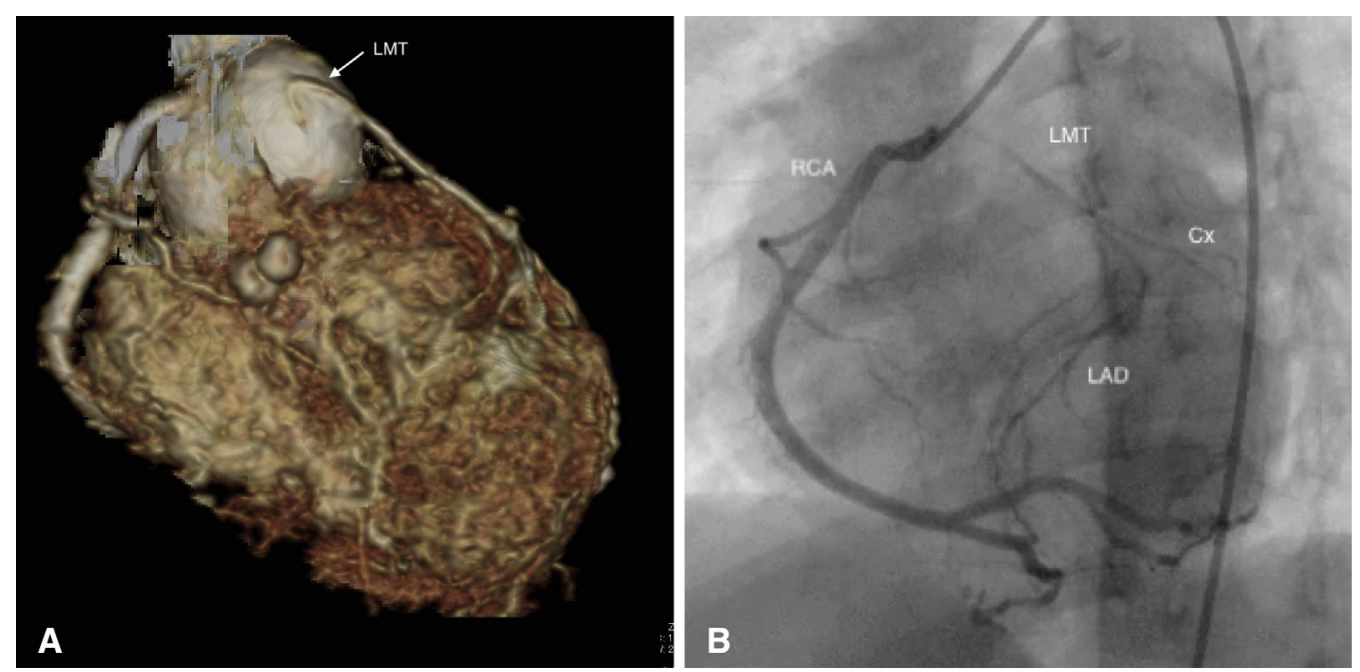

FIGURE 1. A, Preoperative computed tomography showed a dilated sinus of Valsalva with the long and narrow left main trunk artery (LMT) stretched on the sinus. B, Preoperative coronary angiography with contrast injected in the right coronary artery orifice. Obstructed left main trunk artery was opacified retrogradely through many collaterals. The proximal end of the left main trunk artery was as high as the right coronary artery $(R C A)$ orifice. $C x$, Circumflex coronary artery; $L A D$, left anterior descending coronary artery. 

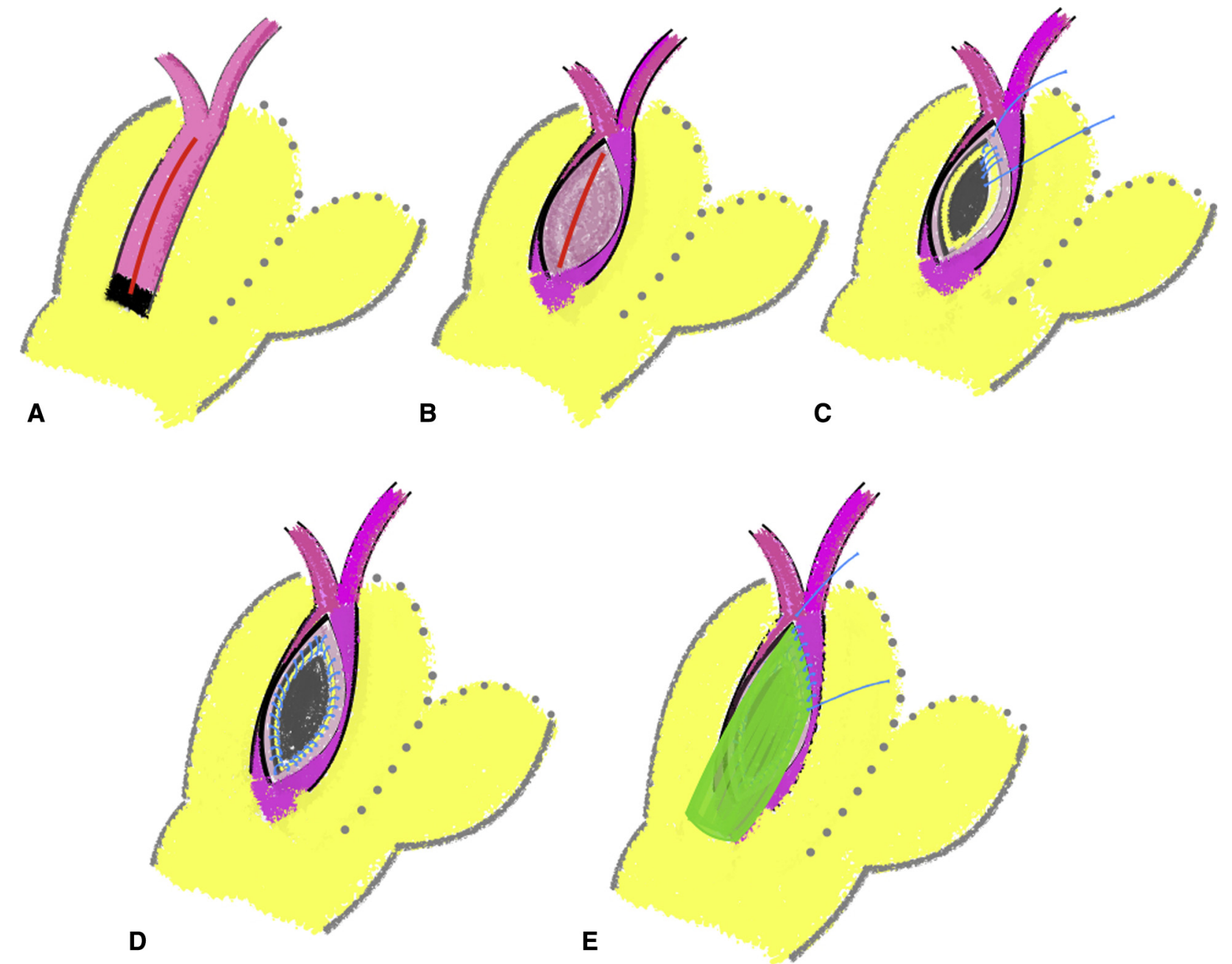

FIGURE 2. A, The anterior wall of the left main trunk artery was opened longitudinally up to near the bifurcation. B, An incision was made into the floor of the coronary artery and the sinus of Valsalva immediately below the coronary artery, to open up into the aorta. C and D, After a portion of the sinus of Valsalva wall was excised to obtain a coronary orifice of sufficient size, the incised coronary floor and the sinus of Valsalva wall were sutured. A new ostium was created. E, The new orifice and a part of the left main trunk artery were covered with an autologous patch of the right pulmonary artery.

3 months revealed that the left coronary artery had no stenosis; however, it was found to be hypoplastic. The sinus of Valsalva was already dilated. At the age of 3 years, the boy's face sometimes turned pale. A 24-hour-electrocardiogram revealed an episode of ventricular tachycardia on 1 occasion. Computed tomography revealed a dilated sinus of Valsalva and a stretched narrow left main trunk coronary artery (LMT; Figure 1, A). Angiography revealed that the LMT was obstructed at the ostium and had opacified with collateral arteries from the right coronary system (Figure 1, B). The patient was referred to our hospital for revascularization of the left coronary system at the age of 4 years. Cardiopulmonary bypass was established with bicaval cannulations and arterial cannulation into the innominate artery. The main pulmonary artery was transected for better exposure of the LMT. The ascending aorta was crossclamped, and cardioplegic arrest was obtained. An attempt was made to open the LMT longitudinally, but the obstructed segment only was incised first. The true

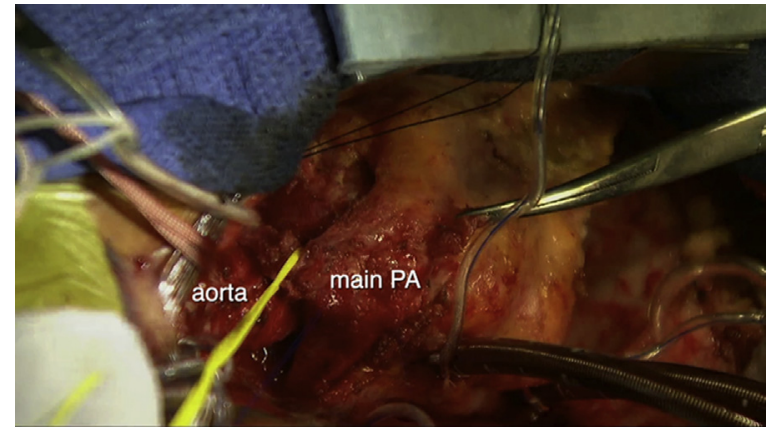

VIDEO 1. The anterior wall of the left main trunk artery $(L M T)$ was opened longitudinally. Normal coronary intima was identified near the bifurcation. An incision was made into the floor of the coronary artery and the sinus of Valsalva immediately below the coronary artery, to open up into the aorta. After a portion of the sinus of Valsalva wall was excised to obtain a coronary orifice of sufficient size, the incised coronary floor and the sinus of Valsalva wall were sutured. The new orifice was covered with an autologous patch harvested from the right pulmonary artery $(P A)$. Video available at: https://www.jtcvs.org/article/S0022-5223(19)30069-8/fulltext. 

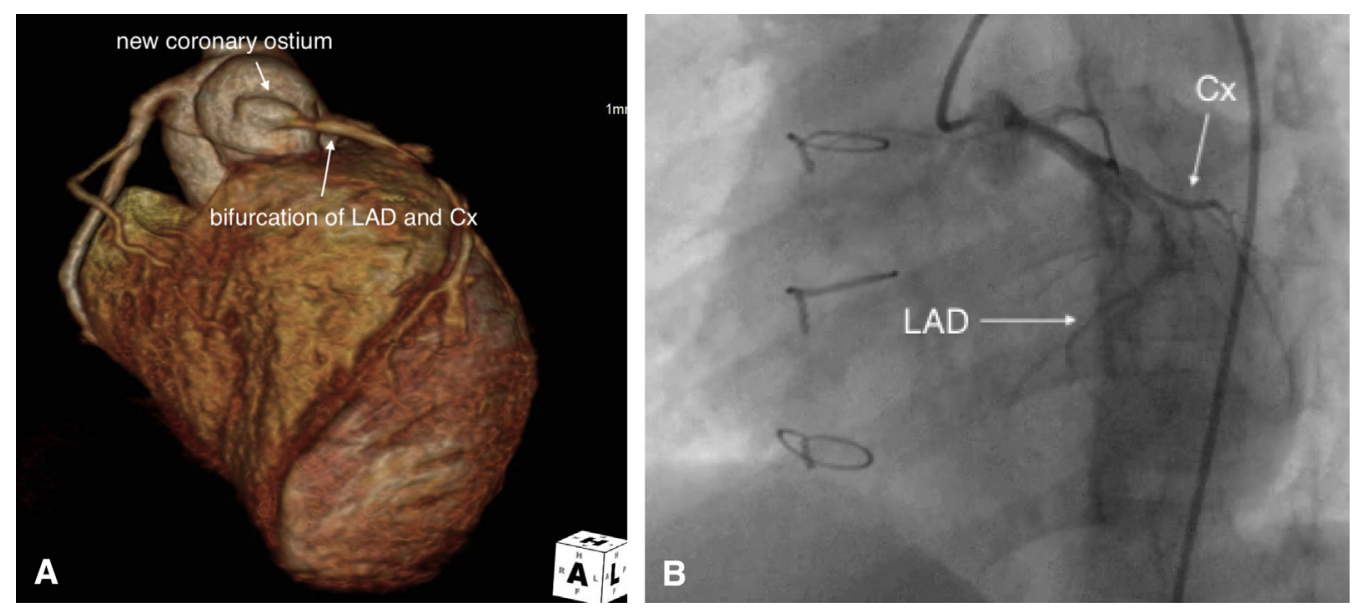

FIGURE 3. A, Postoperative computed tomography. A large new ostium was created lower in the sinus. The left main trunk artery became very short. $\mathrm{B}$, Postoperative angiography showed a patent left main trunk artery. $L A D$, Left anterior descending coronary artery; $C x$, circumflex coronary artery

lumen was reached by advancing a fine forceps bluntly. As shown in Figure 2 and Video 1, the LMT anterior wall was opened to a point near the bifurcation of the left anterior descending and circumflex coronary arteries. Subsequently, an incision was made into the floor of the coronary artery and the sinus of Valsalva immediately below the coronary, to open up into the aorta. After a portion of the sinus of Valsalva wall was excised to obtain a coronary orifice of sufficient size, the incised coronary floor and the sinus of Valsalva wall were sutured. The LMT was covered with a right pulmonary artery wall patch. The right pulmonary artery was reconstructed with a pericardial patch. The postoperative course was uneventful. Postoperative computed tomography and angiography revealed a patent LMT (Figure 3), and the collateral arteries from the right coronary artery had disappeared.

\section{DISCUSSION}

We have demonstrated that the novel patch angioplasty technique provided good results in this 4-year-old boy. Patch angioplasty is advantageous because most physiologic blood flow recommences, and the graft can be saved for bypass grafting in the future if necessary.

In general, coronary buttons are transferred around the sinotubular junction, sometimes above the sinus of Valsalva, to prevent coronary artery kinking in ASO. In this case, the coronary button was possibly placed too high, which can contribute to coronary obstruction. The sinus of Valsalva reportedly has the tendency to dilate after $\mathrm{ASO}^{4,5}$ and it might stretch and compress the LMT, thereby inducing coronary obstruction. This could be another reason. The technique described in this report is useful for treating such coronary obstructions. A new orifice is created at a lower point in the sinus, and the LMT is shortened. Patch angioplasty is more effective and reliable with this modification. The aortic sinus was $25 \mathrm{~mm}$ in diameter. We chose to observe the fate of the sinus. We expect coronary obstruction to never relapse with our technique if the root dilates. Care must be taken not to damage the aortic valve leaflet. In our case, we decided on preoperative computed tomography that the origin of the LMT was far from the aortic cusp and it was safe to enter the sinus through the back wall of the first segment of the LMT. Once we saw the valve from the incision, we could advance the incision with safe.

The right pulmonary artery wall, used as the patch material in this study, has several advantages. It is easy to harvest and handle during suturing. It also has sufficient thickness to prevent a purse string effect, and similar thickness and elasticity compared with the native coronary artery wall.

In conclusion, we successfully performed patch angioplasty for LMT obstruction after ASO by new distal orifice creation to eliminate the long stretched main trunk on the dilated Valsalva sinus.

\section{References}

1. Mavroudis C, Backer CL, Duffy CE, Pahl E, Wax DF. Pediatric coronary artery bypass for Kawasaki, congenital, post arterial switch, and iatrogenic lesions. Ann Thorac Surg. 1999;68:506-12.

2. Raisky O, Bergoend E, Agnoletti G, Ou P, Bonnet D, Sidi D, et al. Late coronary artery lesions after neonatal arterial switch operation: results of surgical coronary revascularization. Eur J Cardiothorac Surg. 2007;31:894-8.

3. Anagnostopoulos PV, Pigula FA, Myers JL, Beerman LB, Siewers RD, Gandhi SK. Autologous patch angioplasty of the left main coronary artery in a pediatric patient: 7-year follow-up. Ann Thorac Surg. 2004;77:1457-9.

4. Co-Vu JG, Ginde S, Bartz PJ, Frommelt PC, Tweddell JS, Earing MG. Long-term outcomes of the neoaorta after arterial switch operation for transposition of the great arteries. Ann Thorac Surg. 2013;95:1654-9.

5. Michalak KW, Moll JA, Moll M, Dryzek P, Moszura T, Kopala M, et al. The neoaortic root in children with transposition of the great arteries after an arterial switch operation. Eur J Cardiothorac Surg. 2013;43:1101-8. 